\title{
Azathioprine induced hepatic veno-occlusive disease in rheumatoid arthritis
}

\author{
DOUGLAS E LEMLEY, LEE M DELACY, LEONARD B SEEFF, \\ KAMAL G ISHAK, AND DAVID J NASHEL
}

From the Divisions of Rheumatology, and Gastroenterology and Hepatology, Department of Medicine Veterans Administration Medical Center and Georgetown University School of Medicine; and the Departmentw of Hepatic Pathology, Armed Forces Institute of Pathology, Washington, DC, USA

SUMMARY A patient with rheumatoid arthritis developed hepatic veno-occlusive diseaseb following the use of azathioprine. Although azathioprine induced veno-occlusive disease is suspected to occur more frequently in patients with autoimmune dysfunction, it has note previously been reported as a complication of treatment in rheumatoid arthritis. The mechanisme responsible for this condition remains unknown.

Recent reviews of azathioprine induced hepatic veno-occlusive disease in recipients of a renal transplant suggest that this poorly recognised drug reaction occurs predominantly in patients with autoimmune dysfunction ${ }^{12}$ or among those with preexisting liver disease. ${ }^{1}$ Our observation of a patient with rheumatoid arthritis (RA) and chronic hepatic necroinflammatory disease of uncertain aetiology, who was found to have histological features of hepatic veno-occlusive disease following the use of azathioprine, further supports this position.

\section{Case report}

In 1983 a 59 year old man with a history of remote alcohol abuse and duodenal ulceration reported the onset of polyarticular pain and swelling. Evaluation showed symmetrical synovial thickening, juxta-articular osteopenia and erosions, and a positive rheumatoid factor. Aspirin and numerous other non-steroidal anti-inflammatory drugs were given, without relief of symptoms. Later trials of sodium aurothiomalate, hydroxychloroquine, D-penicillamine, and prednisone were similarly ineffective.

Accepted for publication 24 August 1988

Correspondence to Dr David J Nashel, Division of Rheumatology, Veterans Administration Medical Center, Room 3A-161, 50 Irving Street, NW, Washington DC 20422, USA.
Azathioprine (50 mg twice daily) was introduce in May 1985, and three months later was followed b? the onset of vague abdominal discomfort. The patient denied recent use of alcohol and gave no history of recurrent melena or haematemesis Although he previously had required blood trans:fusion, there was no known history of clinicalle apparent hepatitis, and he had never abused intra: venous drugs. Physical examination was abnorma only for persistent synovial thickening. No perï cardial rub was present, bowel sounds were active there was no jaundice or enlargement of the liver of spleen, and the stool was negative for occult blood loss. Laboratory data showed white blood cell coun $8.6 \times 10^{9} / 1$, haemoglobin $132 \mathrm{~g} / 1$, and packed ceff. volume $0 \cdot 40$; alkaline phosphatase $1402 \mathrm{nmol} \cdot \mathrm{s}^{-1} / \mathrm{S}$ (normal 217-650), total bilirubin $3.4 \mu \mathrm{mol} / 1$ (normă $0-17$ ), alanine transaminase $408 \mathrm{nmol} \cdot \mathrm{s}^{-1} / 1$ (norma 17-350), and aspartate transaminase $585 \mathrm{nmol} \cdot \mathrm{s}^{-1} / \mathrm{s}$ (normal 117-450). An evaluation of the cause of these abnormalities was not made at that time Rather, in the absence of clinically evident gastro intestinal or hepatic disease prednisone $(10 \mathrm{mg}$ every other day) and aspirin (325 $\mathrm{mg}$ four times 8 day) were continued, hydroxychloroquine $(200 \mathrm{~m}$ 落 twice daily) was resumed, and azathioprine was increased (50 $\mathrm{mg}$ three times a day).

By December 1985 clinical evidence of port\$ hypertension was apparent. The patient was re 8 


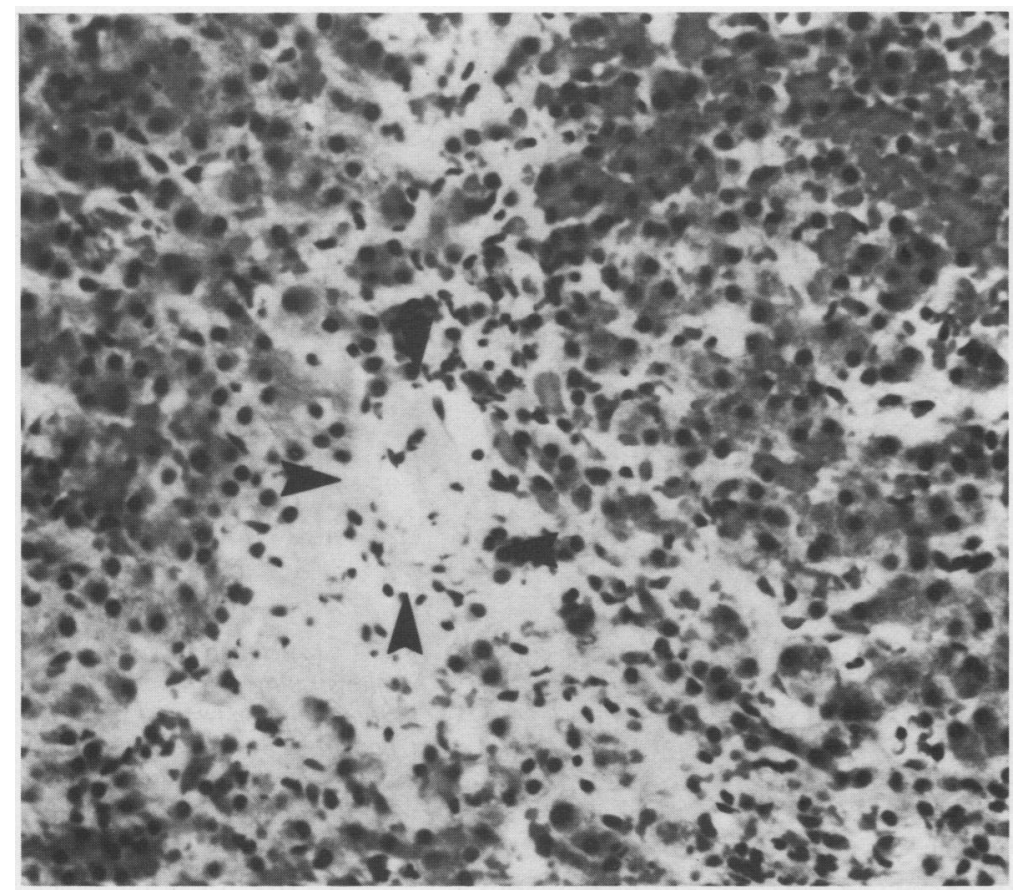

Fig. 1 Liver biopsy specimen showing subtotal occlusion of a terminal hepatic venule (arrow heads). (Haematoxylin-eosin.)

ferred to the Veterans Administration Medical Center, Washington DC, where physical examination showed hepatomegaly, ascites, and peripheral oedema. Significant laboratory results were: alkaline phosphatase $6093 \mathrm{nmol} \cdot \mathrm{s}^{-1} / \mathrm{l}$, total bilirubin $13.6 \mu \mathrm{mol} / \mathrm{l}$, alanine transaminase $986 \mathrm{nmol} \cdot \mathrm{s}^{-1} / \mathrm{l}$, and aspartate transaminase $1722 \mathrm{nmol} \cdot \mathrm{s}^{-1} / \mathrm{l}$. Antismooth muscle and antimitochondrial antibodies were negative as were serological tests for hepatitis B. Coagulation functions were normal; tests for cytomegalovirus were not performed. All drugs except prednisone were discontinued. Ascites partially resolved with bed rest, and repeated hepatic biochemical parameters two weeks after admission were: alkaline phosphatase $4206 \mathrm{nmol} \cdot \mathrm{s}^{-1} / \mathrm{l}$, total bilirubin $20.4 \mu \mathrm{mol} / \mathrm{l}$, alanine transaminase $323 \mathrm{nmol} \cdot \mathrm{s}^{-1} / \mathrm{l}$, and aspartate transaminase $585 \mathrm{nmol} \cdot \mathrm{s}^{-1} / 1$.

Percutaneous biopsy of the liver showed the acute and chronic changes of veno-occlusive disease, with marked centrilobular congestion, sinusoidal dilatation, and scattered foci of non-thrombotic sclerosis of terminal hepatic venules with adjacent hepatocellular necrosis (Fig. 1). Mild periportal fibrosis and patchy piecemeal necrosis were also noted and were considered to be related to probable non- $A$, non-B hepatitis as the consequence of prior blood transfusion. No abnormalities of the portal vasculature were apparent (Figs $2 a$ and $2 b$ ), and the biopsy specimen showed no evidence of vasculitis, amyloidosis, or nodularity.

Although active RA, mild ascites, and raised alkaline phosphatase values $\left(3300-3800 \mathrm{nmol} \cdot \mathrm{s}^{-1} / \mathrm{l}\right)$ persist 30 months after treatment with azathioprine was stopped, there has been no clinical evidence of progressive portal hypertension despite subsequent trials of prednisone, sulindac, hydroxychloroquine, gold, and sulphasalazine.

\section{Discussion}

Azathioprine induced hepatic veno-occlusive disease has been reported as a complication of antirejection treatment in recipients of a renal transplant $^{12}$ and of chemotherapy in patients with leukaemia. ${ }^{3}$ It is characterised histologically by hepatic congestion, non-thrombotic occlusion of centrilobular hepatic venules with perivenular necrosis and fibrosis, and perisinusoidal fibrosis with sinusoidal dilatation. ${ }^{12} 4$ These changes are subtle, however, and detection depends not only upon the quality of the biopsy specimen but also upon the experience of the reviewing pathologist. ${ }^{12}$

Hepatic veno-occlusive disease typically is charac- 


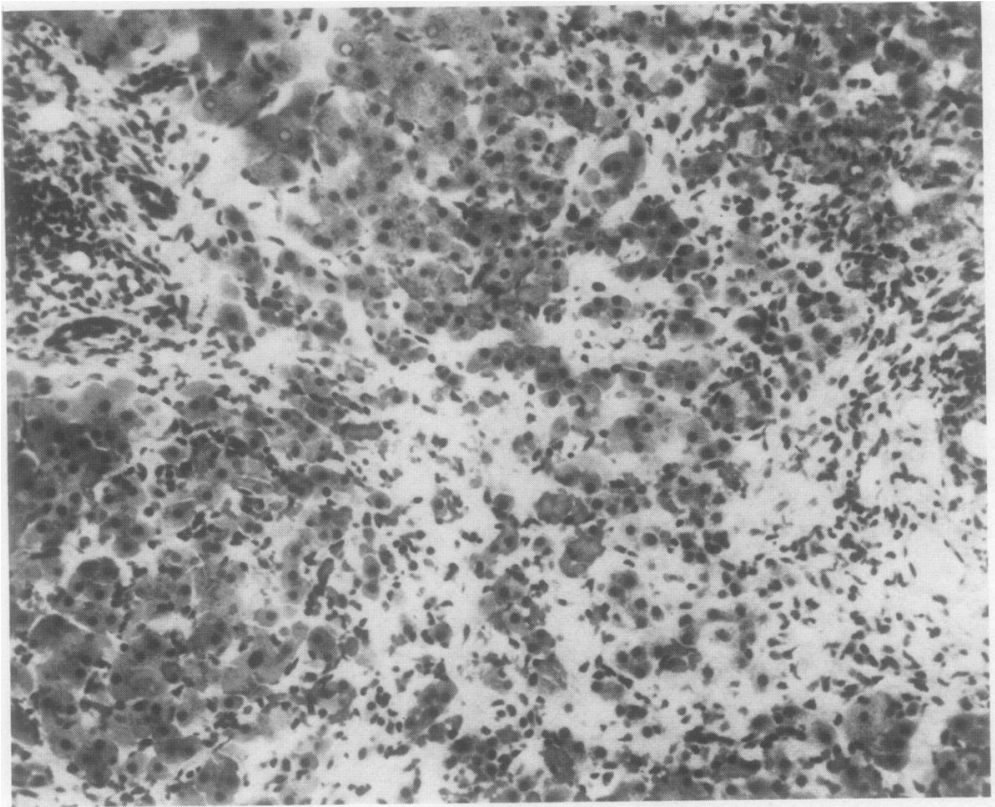

Fig. $2 \mathrm{a}$

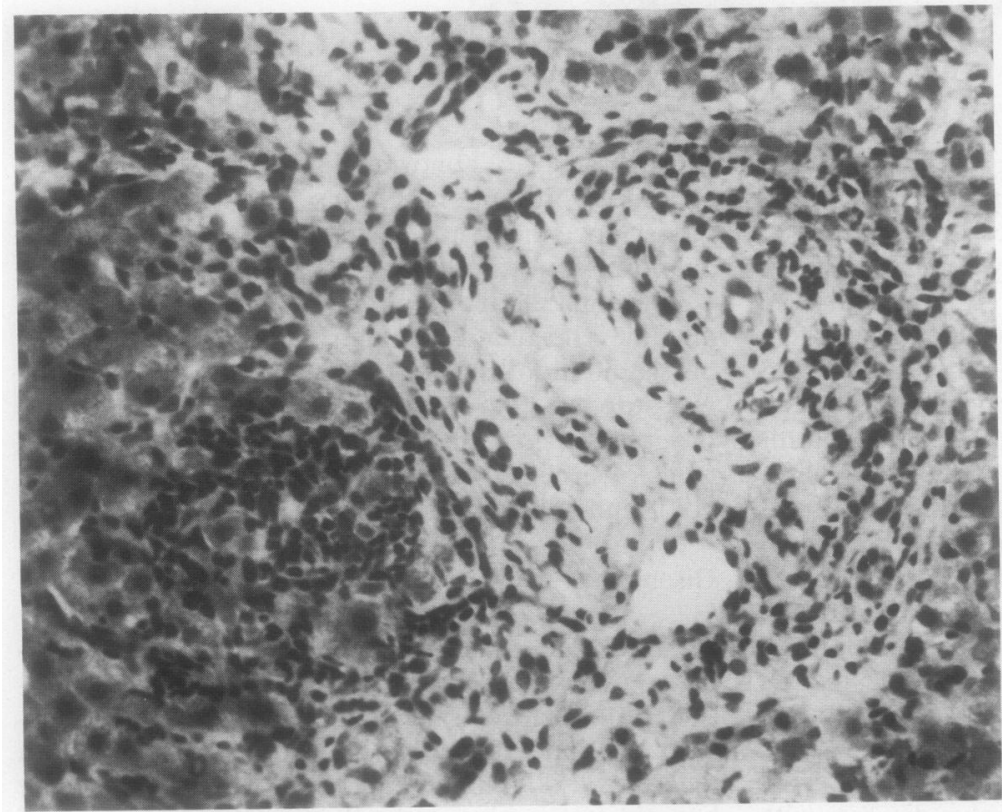

Fig. 2b

terised by the triad of jaundice, hepatomegaly or right upper quadrant abdominal pain, and ascites or sudden weight gain. ${ }^{5}$ The diagnosis is difficult to establish. The spectrum of presenting symptoms is wide, ranging from mild abdominal discomfort to liver failure and death. ${ }^{2} 6$ Hepatic biochemical
Fig. 2 (a) Hepatic tissue demonstrating patchy inflammation in two portal areas (right and left). Zone 3 (central zone) shows fibrosis and atrophy of liver cell plates.

(Haematoxylin-eosin.) (b) Ill defined junction between hepatic parenchyma and portal area with mononuclear cell infiltration (piecemeal necrosis).

(Haematoxylin-eosin). abnormalities are non-specific. Also, it is difficult tōo attribute the liver dysfunction exclusively tQ azathioprine in most subjects in whom it is use $\$$ because of the simultaneous administration of othe potentially hepatotoxic drugs.

Further confusing the issue is the intrinsic hepatic 
dysfunction that occasionally develops owing to RA itself. It is usually benign with only modest increases of transaminases or histological evidence of mild periportal inflammation, ${ }^{7}$ but necrotising arteritis may occur within the liver in severe systemic disease. ${ }^{8}$ Nodular regenerative hyperplasia occurs relatively frequently in Felty's syndrome, ${ }^{910}$ but it has been reported in simple RA only rarely. 91112 Similarly, the prevalence of primary biliary cirrhosis is higher in Sjögren's syndrome complicating RA than in RA alone. ${ }^{13}$ The hepatotoxicity of uncomplicated RA is more commonly drug related. ${ }^{7}$ Reversible hepatocellular or cholestatic abnormalities, or both, have been noted following the use of aspirin ${ }^{14}$ and other non-steroidal anti-inflammatory drugs, ${ }^{7}$ D-penicillamine, ${ }^{15}$ and gold. $^{716}$ Azathioprine too may cause chemical evidence of liver dysfunction or nausea, vomiting, and abdominal pain when administered to patients with RA. ${ }^{17} 18$ Nodular regenerative hyperplasia has been reported once in a patient with RA treated with this drug. ${ }^{12}$ Until now, however, histological evidence of hepatic venoocclusive disease has not been observed following its use in this population.

The abnormalities in serum enzymes noted in this patient indicate the presence of underlying chronic necroinflammatory disease. Although there was a positive history of drinking, alcohol use was not a plausible explanation for the enzyme abnormalities as the patient was now abstinent, the biochemical changes were not consistent with alcohol use, and the histology was not compatible. Thus although the aetiology of this disorder was not determined, the pattern of biochemical abnormalities and the presence of piecemeal necrosis (a histological change that is consistent with though not necessarily pathognomonic of chronic hepatitis) supported the diagnosis of chronic non- $A$, non-B hepatitis, particularly in view of previous blood transfusion.

Three cases of veno-occlusive disease proved by biopsy have been reported in association with systemic lupus erythematosus. ${ }^{2} 1920$ DePinho et al noted the development of scleral icterus and raised hepatic biochemical parameters three weeks after the start of treatment with azathioprine $(100 \mathrm{mg}$ daily) in a young man with active systemic lupus erythematosus and renal failure. Biochemical abnormalities resolved within two weeks of the discontinuation of azathioprine. ${ }^{19}$ Katzka and colleagues described the onset of hepatomegaly, scleral icterus, and increased alkaline phosphatase and total bilirubin values after one year of azathioprine treatment (50 mg daily) in a man with inactive systemic lupus erythematosus who had undergone renal transplantation. Symptoms resolved upon cessation of azathioprine and recurred upon re- challenge. ${ }^{2}$ Repeat liver biopsies were not performed in either of these patients. The role of azathioprine in the induction of veno-occlusive disease in systemic lupus erythematosus is brought into question by Pappas et al, however, who reported the development of clinical evidence of hepatic dysfunction in concert with histological evidence of veno-occlusive disease in a young woman with active systemic lupus erythematosus who had neither undergone renal transplantation nor received azathioprine. A brief trial of azathioprine failed to affect her ascites, and repeat liver biopsy showed no significant changes following the azathioprine treatment. The authors concluded that the pathogenesis of veno-occlusive disease in systemic lupus erythematosus is unknown but postulated that it may be related to underlying vasculitis. ${ }^{20}$

The development of azathioprine induced hepatic veno-occlusive disease has been associated with either pre-existing autoimmune dysfunction or liver damage, ${ }^{12}$ but a mechanism for the establishment of this vascular abnormality remains unknown. The presence of both immumological defects and incidental liver damage (as a result of possible viral hepatitis or the effects of alcohol ingestion, or both) in this case supports this position, but it unfortunately does not provide a better definition of the pathogenesis of veno-occlusive disease. It seems unlikely that RA alone contributes to the establishment of this disorder. Despite years of experience with azathioprine in RA, veno-occlusive disease has never previously been reported in this population. ${ }^{21}$ Although no true association between these entities may in fact exist, it is also possible that the lack of more frequent recognition of azathioprine induced veno-occlusive disease in RA reflects the usual benignity of hepatic pathology in $\mathrm{RA},{ }^{7}$ as well as the subtle histological features and variable presenting symptoms which may characterise hepatic venoocclusive disease. ${ }^{126}$ Additionally, the role of preexisting abnormalities of hepatic structure or function, perhaps resulting in altered metabolism of azathioprine and the subsequent development of veno-occlusive disease independent of autoimmune phenomena, cannot be excluded.

Thus administration of azathioprine should be attended with knowledge of the serious consequences that may occur with it use. It should be discontinued immediately in any patient who develops hepatic biochemical abnormalities, hepatomegaly, or other clinical evidence of portal hypertension, and a liver biopsy should be performed to confirm the presence of veno-occlusive disease. Heightened awareness of this potentially fatal complication in patients with RA who are treated with azathioprine may increase the frequency of its diagnosis. 


\section{References}

1 Read A E, Wiesner R H, LaBrecque D R, et al. Hepatic venoocclusive disease associated with renal transplantation and azathioprine therapy. Ann Intern Med 1986; 104: 651-5.

2 Katzka D A, Saul S H, Jorkasky D, Sigal H, Reynolds J C, Soloway R D. Azathioprine and hepatic ven-occlusive disease in renal transplant patients. Gastroenterology 1986; 90: 446-54.

3 Woods W G, Dehner L P, Nesbitt M E, et al. Fatal venoocclusive disease of the liver following high dose chemotherapy, irradiation, and bone marrow transplantation. Am J Med 1980; 68: $285-90$.

4 Zafrani E S, Pinaudeau Y, Dhumeaux D. Drug-induced vascular lesions of the liver. Arch Intern Med 1983; 143: 495-500.

5 Rollins B J. Hepatic veno-occlusive disease. Am J Med 1986; 81: 297-305.

6 Paulus H E, Williams H J, Ward J R, et al. Azathioprine versus D-penicillamine in rheumatoid arthritis patients who have been treated unsuccessfully with gold. Arthritis Rheum 1984; 27: 721-7.

7 Schenker S, Olson K N, Dunn D, Breen K J, Combes B. Intrahepatic cholestasis due to therapy of rheumatoid arthritis. Gastroenterology 1973; 64: 622-9.

8 Ball J. Rheumatoid arthritis and polyarteritis nodosa. Ann Rheum Dis 1954; 13: 277-90.

9 Wanless I R, Godwin T A, Allen F, Feder A. Nodular regenerative disorders of the liver in hematologic disorders: a possible response to obliterative portal venopathy: a morphometric study of nine cases with an hypothesis on the pathogenesis. Medicine (Baltimore) 1980; 59: 367-79.

10 Thorne C, Urowitz M B, Wanless I, Roberts E, Blendis L M. Liver disease in Felty's syndrome. Am J Med 1982; 73: 35-40.

11 Harris M, Rash R M, Dymock I W. Nodular, non-cirrhotic liv associated with portal hypertension in a patient with rheumatoid arthritis. J Clin Pathol 1974; 27: 963-6.

12 Stromeyer F W, Ishak K G. Nodular transformation (nodula? "regenerative" hyperplasia) of the liver: a clinicopathologe study of 30 cases. Hum Pathol 1981; 12: 60-71.

13 Whaley K, Goudie R B, Williamson J, Nuki G, Dick W (e) Buchanan W W. Liver disease in Sjögren's syndrome an rheumatoid arthritis. Lancet 1970 ; i: $861-3$.

14 Zimmerman H J. Effects of aspirin and acetaminophen on the liver. Arch Intern Med 1981; 141: 333-42.

15 Rosenbaum J, Katz W A, Schumacher H R. Hepatotoxici $\vec{\Phi}$ associated with use of D-penicillamine in rheumatoid arthritis. Ann Rheum Dis 1980; 39: 152-4.

16 Favreau M, Tannenbaum H, Lough J. Hepatic toxicity assoc. ated with gold therapy. Ann Intern Med 1977; 87: 717-9.

17 Cooper C, Cotton D W K, Minihane N, Cawley M I D? Azathioprine hypersensitivity manifesting as acute focal hepat cellular necrosis. J R Soc Med 1986; 79: 171-3.

18 Assini J F, Hamilton R, Strosberg J M. Adverse reactions azathioprine mimicking gastroenteritis. $J$ Rheumatol 1986; 130 1117-8.

19 DePinho R A, Goldberg C S, Lefkowitch J H. Azathioprin and the liver: evidence favoring idiosyncratic, mixed cholestatic-hepatocellular injury in humans. Gastroenterology 198 86: $162-5$.

20 Pappas S C, Malone D G, Rabin L, Hoofnagle J H, Jones E A. Hepatic veno-occlusive disease in a patient with systemic lupus erythematosus. Arthritis Rheum 1984; 27: 104-8.

21 Hunter T, Urowitz M B, Gordon D A, Smythe H A, Ogryzlo M A. Azathioprine in rheumatoid arthritis: a long-term follow up study. Arthritis Rheum 1975; 18: 15-20. 